DOI: $10.15503 /$ jecs20142.93.101

Journal of Education Culture and Society No. 2_2014

\title{
THE IMPACT \\ OF VOICE ON SPEECH REALIZATION
}

\author{
JELKA BREZNIK \\ Faculty of Arts, University of Ljubljana, \\ Aškerčeva 2, Lubjana, Slovenia \\ E-mail address: jelka@govornik.si
}

\begin{abstract}
The study discusses spoken literary language and the impact of voice on speech realization. The voice consists of a sound made by a human being using the vocal folds for talking, singing, laughing, crying, screaming... The human voice is specifically the part of human sound production in which the vocal folds (vocal cords) are the primary sound source. Our voice is our instrument and identity card. How does the voice (voice tone) affect others and how do they respond, positively or negatively? How important is voice (voice tone) in communication process? The study presents how certain individuals perceive voice. The results of the research on the relationships between the spoken word, excellent speaker, voice and description / definition / identification of specific voices done by experts in the field of speech and voice as well as non-professionals are presented. The study encompasses two focus groups. One consists of amateurs (non-specialists in the field of speech or voice who have no knowledge in this field) and the other consists of professionals who work with speech or language or voice. The questions were intensified from general to specific, directly related to the topic. The purpose of such a method of questioning was to create relaxed atmosphere, promote discussion, allow participants to interact, complement, and to set up self-listening and additional comments.
\end{abstract}

Keywords: voice, speech, speaker, spoken literary language

\section{INTRODUCTION}

Communication is the primary function of speech. We usually consider speech as a common characteristic of all living creatures, but this is not entirely the case, since speech is definitely specific and unique for each individual. Many people take it for granted: they believe it is a skill which we acquire in childhood and later upgrade. If we talk about voice culture, then speech is a field which needs to be developed, and if we consider speech as a profession, it needs to be improved constantly. For professional speakers professional qualifications are essential. It is a long-lasting process which requires considerable knowledge of grammar, pronunciation, speech and breathing techniques (Stankovič, 2011, p. 1-2). 
Speech is a rich mean of expression allowing an individual to voice their comments on an idea while pronouncing it - in order to express agreement, disagreement, happiness, surprise, excitement (Vuletić, 1980, p. 37). Speakers, even professionals, who control their speech and language, are usually not aware of the consistency of voice tools (speech), voice and gestures.

When practicing their profession, professional speakers entirely dependent on their voice, and any voice disorder may prevent the performance of work (Lemke, Montequin, \& Titze, 1997, p. 254).

Professional voice users depend on vocal endurance and quality for their livelihood. The prevalence of dysphonia in certain subsets within this group can be extremely high (Lerner, Paskhover, Acton, \& Young, 2013, p. 705).

Their constant voice use, or vocal load, required occupationally may lead to voice difficulties. Factors in the work environment may contribute to vocal difficulty, including high levels of background noise, poor environmental acoustics, and poor atmospheric humidity. Those persons with high vocal quality demands, such as radio announcers and singers, are more likely to recognize changes in their voices and to seek assistance for voice problems than those persons in occupations with lower voice quality demands (Wingate, Brown, Shrivastav, Davenport, \& Sapienza, 2007, p. 434).

All voice professionals must be familiar with the structure of voice production, recognition of symptoms of voice problems, preventive measures for maintaining voice quality, exercises for maintaining voice quality, phonetic therapeutic vocal exercises (Varošanec-Škarić, 2010, p. 39). Vocal therapists, phonetics and vocal pathologists agree that in order to prevent voice problems it is necessary to regularly practice vocal exercises (Sataloff, Spiegel, Hawkshaw, \& Heuer, in Varošanec-Škarić, 2008, p. 881).

In Slovenia, the preparation of oral presentation is mainly focused on the content, the structure, the choice of words - while voice performance, in terms of techniques of speech and voice, is not a priority. Why experts in the field of speech ignore attaching the voice a special interest, if we all know that without the voice there is no speech. Furthermore, in the Slovenian area there is no professional platform for the evaluation of speech or voice, nor common terminology which would help experts to describe speech execution or voice in speech analysis with exception of phoniatry and logopedy. Each expert individually decides what terminology / methods he/she will use. Decisions are made based on past experience and their own judgment. There is no predefined terminology in the Slovenian area. The aim of the study was to determine the attitude of experts toward the speech and voice and compare it with the laymen, and to identify whether they distinguish voice from speech.

\section{SPEECH PREPARATION}

Numerous studies and expert meetings with fellow phoneticians and linguists have revealed that verbal preparation is based primarily on managing normative language. When it comes to professional speakers: announcers (radio announcers), actors, journalists, presenters articulation preparation is also important. However, the focus on voice is entirely neglected. Already Cicero emphasized the importance of good voice and good voice performance and particularly stressed the importance of vocal color (pleasant voice color), tone of voice (high, deep), speech tempo (fast, slow), strength (good, bad) and volume (Varošanec-Škarić, 2010, p. 18). 
When considering spoken word, we actually mean phonological word, and when considering written word, we actually mean the spelling of the word. Both written and spoken words are associated with the language (Stankovič, 2013, p. 2). However, without good, healthy voice we are not able to properly form and shape voices, pronounce words, create melodic sentences and intriguing longer spoken compositions.

Past experiences in the field of speech, voice training and voice analysis have shown that radio-announcers, TV-presenters and actors are the most skillful speakers. In professional circles it is often assumed that the speech realization of a skilled speaker is based on his/ her oral and articulation preparation for a public performance. This does not simply mean that the skillful speaker only masters pronunciation norms, the duration, position and type of stress, but also a clear, comprehensible and fluent speech. High level of awareness of the cultivation of speech and the culture of spoken language, knowledge of the speech techniques, voice, breathing, taking care of voice and capabilities of one's own speech organs are expected. This assumption is also the basis for an expert analyzing professional speakers. However, these thoughts led to a deeper speech analysis of professional speakers and their speech and articulation preparation for public performance (Stankovič, \& Tivadar, 2013, p. 3-4).

Professional voice users place considerably more demands on their vocal mechanisms when using their voice in acting than during normal speech patterns. Actors require considerable training to adapt to professional voice use in terms of controlling and coordinating articulation, breathing, and phonation. On a number of variables, individuals with formal voice training produced measurable differences compared to those without such training. These differences include phonatory behavior, contact area of the vocal folds, pitch and loudness control, and glottal adduction during increased vocal intensity (Swisher, et al., in Zeine, \& Waltar, 2000, p. 229). It is logical to assume that in acquiring a refined vocal technique, trained actors would gain increased knowledge of the anatomy, physiology, and care of the vocal mechanism, including the role of the speech-language pathologist and the voice (Zeine, \& Waltar, 2000, p. 229).

All tested, proven and effective methods of vocal exercises have their own scientific explanations that have been evaluated and verified. Scientifically and practically founded phonetic exercises for voice and pronunciation are based on certain principles some are founded from the time when particular aesthetic importance was attributed to voice production, others are founded on new scientific discoveries in the field of voice production obtained through the development of technical capabilities for measuring voice quality parameters (Varošanec-Škarić, 2010, p. 30).

Vocal and pronunciation exercises occurred for the purpose of phoneticians in connection with functional rehabilitation of dysphonia as therapeutic exercises for vocal professionals in order to functionally strengthen the voice of vocal professionals (Varošanec-Škarić, 2010, p. 57).

The first thing in phonetics is to determine the voice quality: normal, pathological or nice (aesthetic) (Varošanec- Škarić, 2010, p. 108).

Usually voice assessment is carried out by means of multi-stage scale. However, when the phonetic protocol is used in clinical phonetics (Varošanec-Skarić, 2010, p. 268$269)$, the forms of impostation are evaluated on the basis of two listenings. The first listening evaluates whether the imposition is neutral. Neutral can be defined as either normal or abnormal. The protocol of vocal profile or VPA consists of three parts. In the first part, forms of vocal quality in the categories of over glottal forms and glottal forms are analyzed, in the second prosodic forms (tone, firmness, volume), and in the third time organization (smoothness, continuity, speed) (Varošanec-Škarić, 2010 p . 111). 
Several studies have been made to structurize terminology to describe voices, and different systems, to analyze voice quality perceptually have been developed. However, most studies are primarily developed for the evaluation of pathological voices (Velsvik Bele, 2007, p. 257).

In relation to the health of the voice, there are different multi-dimensional protocols for evaluating voice which include questionnaires on anamnesis of voice for voice professionals. They are used by doctors - otorhinolaryngology, phoniatricians, speech therapists, questionnaires on the daily habits, voice care, smoking habits, diet, vocal abuse (Varošanec-Škarić 2010, p. 122).

Thus, speech pathologists in relation to the care of voice, pedagogic voice, use a protocol that consists of four integral wholes (Varošanec-Škarić 2010, p. 125):

a) Symptoms of problems with the voice.

b) Risk factors that can lead to the development of problems with the voice.

c) Tension of the voice.

d) Daily use of the voice.

Below the results of the research on the relationships between the spoken word, excellent speaker, voice and description / definition / identification of specific voices done by experts in the field of speech and voice as well as non-professionals are presented.

\section{METHODOLOGY}

The study encompasses two focus groups. One consists of amateurs (non-specialists in the field of speech or voice who have no knowledge in this field) and the other consists of professionals who work with speech or language or voice. The first group was formed of six people and the second group was formed of five people. The questions were intensified from general to specific, directly related to the topic and coordinated by a moderator who makes sure that the conversation is recorded. The conversation in the first focus group lasted approximately 120 minutes and $150 \mathrm{mi}-$ nutes in the second. The purpose of such method of questioning was to create relaxed atmosphere, promote discussion, allow participants to interact, complement, and to set up self-listening and additional comments.

The questions were divided into preliminary, transitional and key. Preliminary questions referred to the importance of the spoken word, the awareness of the manner of speaking - I was interested whether the participants think about how they speak, what impression they make on the listeners and interlocutors, what the difference between the spoken and written word is, what kind of speaker is in their opinion a good speaker, how would they describe him/her, do they believe it is important to become a good speaker, what is cultivated speech and who do they believe is a cultivated speaker. Transitional questions directly referred to speech and voice. I was interested in what is the first thing they notice about the speaker, do they alter voice and the manner of speech, what is most disturbing in the speaker, does the speaker's voice at any time disturb or excite them, which public figure has a pleasant voice.

Key questions were more detailed. I was interested in what is a pleasant voice in their opinion, how would they describe it and what is a poor voice. The participants had to list at least five characteristics of voice, specify what can be determined on the 
basis of voice, how would they describe specific voice as for example: authoritative, nervous, underestimating, cowardly, brave, pleasant and unpleasant. Due to the fact that key questions were intended for deeper understanding of the voice, the participants were given a task to determine voice aesthetics, tone, physical properties (gender, age, state of health - in terms of whether it is a healthy voice), register, cultivation, intensity, mood of the voice on the broadcasted recording. The participants listened to 41 audio tracks, 21 foreign, 20 Slovenian recordings which included singers, actors and TV-presenters. Altitude range covered different voices: soprano, mezzo-soprano, alto, countertenor, tenor, baritone, bass-baritone, bass. I was also interested in their opinion on the voice care.

\section{THE FINDINGS OF IN-DEPTH INTERVIEWS}

Due to the scale of the analysis below, I shall only summarize the findings.

The group of randomly selected participants, who were not professionally associated with the area of study, describes the spoken word only as a mean of communication and implementation of grammar in practice. This group believes that the manner of speaking is adapted to different situations, and that it is more important to be understood in communication than to be focused on the way one speaks. According to the group tone, intonation, pitch and timbre of voice additionally inform the listener. A good speaker is described as empathic, comprehensive, credible, relaxed, and familiar with the content of the speech and also with the audience. Cultivated speech is associated with good manners: cultivated speaker is described as the person who lets his interlocutor finish his thoughts, does not interrupt, condemn and who is not cynical and respects the opinion of the others and adjusts his speech to different situations.

The first things they notice about the speaker are: speech impediment, tone of voice, state of relaxation, incorrect use of words, intonation, body language in connection with speech, very low or high-pitched voice and everything that deviates from the average. This group believes that low self-confidence, contradiction, speech impediment, distinctively high tone of voice, disrespect of interlocutors, distinctive intensity of voice, distinctive literary language and incomprehensibility are the most disturbing. The participants in this group had different opinions on the separation of voice from speech; however, they all agreed that they enjoy pleasant, melodic voices which they associate with modes of speech; some of them stated that they are not focused on the voice itself. They listed three public figures who they believe have charming voices: Ivan Lotrič, Pavle Ravnohrib and Jure Longyka.

Pleasant voice was described as velvet and unpleasant as sharp, chirping. In doing so, they have some problems describing particular voice: velvet voice was described as a voice that caresses the ear, while sharp voice was described as unpleasant. In the description such voice was compared with the sound of chisel or chalk being drawn on a board. They said that they were in favor of low-pitched voices, low frequency and not high-pitched voices, high frequency. The following features are attributed to voice: sharp, warm, cold, beautiful, poor, sweet, sour, chirping, melodic, singing, rhythmic, loud, quiet, annoying, pleasant, calming, hectic, strong, energetic, weak. When analyzing the timbre of the voices recorded they evaluated voices on the basis whether they liked or disliked the tone of voice, for example the timbre of the voice was either pleasant or unpleasant. In doing so they often associated the timbre of the voice with 
the manner of speaking and articulation. They said: "crashes, a little extended", "distorted as if swallowed", "speaks with his/her mouth closed", "film voice", "determined", "self-confident".

The participants did not have any problems with the perception of voice, since the evaluation was based on personal perception and evaluation, in particular the melody. Individual's mood was also evaluated in the same manner. Specifying the register did not evoke any complications whatsoever, however, the group had some problems with identifying whether the voice is cultivated - they were distracted by other voices, i.e. recordings of individuals who spoke English which is not their native language. In determining the gender, age and health of the voice the group did not have any problems - the exception was the recording of Lauren Bacall who has a distinctive low-pitched voice as for a woman, and therefore everyone believed that it was a man's voice.

The group of experts in the field of language, speech, acting, singing or music are more aware of the importance of the spoken word. They attach great importance to the spoken word, especially within their field of expertise. Spoken word is associated with the culture of speech and they believe that it is very important in the process of learning a language. They are aware of how they speak, the way they speak and their oral performance. Experts in the field of singing and playing added that they pay more attention to the content, sound of the words, melody of speech, breath and pace of speech. This group believes that spoken word compared with the written one is already a part of the interpretation and that there is a difference in duration and the number of words - more words are used in oral communication. Good public speaker is someone who makes an impression and is energetic with a pleasant tone of voice, speaking skills and lightness of speech. This group is especially aware of errors, deviations from the norm and irregular accents. In their opinion lower voices with clear, pure tone and timbre are more pleasant.

Negative voices in their opinion are: strident, aggressive, raucous, high-pitched. They pointed out that a good speaker is someone who is heard and consistent, meaning that he/she has consistent thoughts, words and facial expressions and body language. The participants pointed out that elegance, easiness, lightness of speech are also important. Cultivated speaker is described as someone who is well familiar with language norms and speaks formal language. They pointed out that rich vocabulary as well as the clarity and conciseness of communication are very important. They also mentioned speech technique, arguing that the proper vocal formation is important for managing speech techniques. The first thing they notice about the speaker is the timbre of voice, speech impediments, accents, dialect, unease, aggressiveness and unwillingness. They positively evaluated a speaker's ability to interact with the audience, and being able, at the same time, to be relaxed, gallant. The most disturbing, in their opinion, is an excessive use of filler words, unwillingness and inappropriate tone of voice. They distinguish between voice and the method of speech, on which they place great importance. In doing so they enumerated a few people who in their opinion have pleasant voices: Jure Longyka, Nataša Dolenc, Ajda Kalan, Primoz Pirnat, Andrej Karoli, Aleš Valič, Natasa Barbara Gračner. According to them, negative voices supplemented by the manner of speech can foremost be heard on commercial radio television.

The participants in this group listed the following characteristics of voice: timbre, register, volume, velvetness, strength, purity and health. In evaluating the recordings they determined the timbre of voice by an appropriate adjective or description of voice. In some cases, the timbre was determined from the context or cultural environment 
(for example Asian voices). It seemed that they do not have any experience with the evaluation of voices. Actors shape their voice according to their role and associate it with articulation and manner of speech. Professionals who have been working at radio stations are particularly focused on velvetness of the voice, which is a measure of a likable or particularly aesthetic voice. In this context metallic voice was also mentioned. Sometimes they focused on the manner of speech trying to express an appropriate term to describe voice - just like nonprofessionals. Their description also included roughness of the voice, softness of the timbre and clarity of the voice. In comparison with the nonprofessional group they did not focus on the mood that was heard in the recordings, as they were aware that each recording is from a different context. Their description often included the register which was the basis for determining the likeability of voice; they also tried to find an appropriate term to describe a particular voice. They did not have any problems with determining and defining the health of a voice (healthy: yes or no). They soon recognized rough, hoarse, cracked voice.

\section{CONCLUSION}

As a mentor and a teacher of speech I attach great importance to voice, not just because nice and healthy voices are pleasing to the ear, but because voice is the basis of speech. Without voice there is no speech, and without a nice, healthy voice there is neither good and quality pronunciation nor a good speaker. I expected the group of experts to pay more attention to voice; however, the study reveals that there is low awareness of voice, since in the preparation of public speakers (with the exception of singers), the experts do not devote any special attention to the voice, neither in the sense of voice care, nor in terms of searching voice techniques. It is interesting though that during listening to the recordings, mostly pleasant modal voices attracted their attention. Voices that were heard were described with adjectives, based on their own perception / understanding of the heard voice. Due to the fact that there is no specific terminology in our area, they optionally selected words in order to describe a specific voice.

Preparation for oral performance, at least in terms of public speakers, should be based on body relaxation, warming up voice organs, breathing techniques, speech and voice, good articulation, formation and implementation of speech with respect to language functions, knowledge and mastering of pronunciation norms. The aim of thorough preparation for oral performance is logical segmentation, intelligibility, clarity and credibility of communication. In other words, if the pronunciation is correct and only the body or part of the body is stressed, this is heard in the voice. The voice is our identity card and any tension or emotion affects voice quality; therefore it is important to be aware of the impostation of voice: phonational as well as articulative and respiratory.

Professional voice users are most susceptible to functional voice pathologies because of improper or excessive voice use (Broaddus-Lawrence, Treole, McCabe, Allen, \& Toppin, 2000, p. 59).

Ineffective voice behavior / use is trained and produced with little, if any at all, awareness. Voice therapy requires patience, a lot of attention and effort in order to change behavior which was unconscious. Therapy requires self-regulation. Self-regulation requires from an individual to learn how to control and change his/her thoughts, feelings and behavior. 
Voice can be trained with proper exercises. It can be enriched and its position can be drawn closer to the ideal of each individual - that is to create a modal voice of each individual, the position of the voice in which the vocal cords are the least affected and the voice sounds pleasant. For professional speakers, the quality of voice is very important, not due to proper speech execution, but also because the timbre of the voice can attract or distract the audience.

Professional voice users' livelihoods depend partially or wholly on the ability to produce voice and include, but they are not limited to, teachers, ministers, salesmen, telemarketers, telephone operators, actors, singers, radio/TV announcers, and attorneys. Although vocal sophistication, voice quality, and vocal load may vary, professional voice users share a dependence on vocal endurance (Wingate, Brown, Shrivastav, Davenport, \& Sapienza, 2007, p. 433-434).

Problems reported by professional voice users are varied and may include hoarseness, voice breaks or cracks, voice loss, weak voice and vocal fatigue. Related physical complaints include shortness of breath dry throat scratchy sensation in the throat, throat discomfort, tightness, or pain and effortful speaking. Chronic voice problems may result in laryngeal irritation and edema or in benign vocal fold lesions, including vocal fold nodules, polyps, hemorrhages, and cysts (Wingate, Brown, Shrivastav, Davenport, \& Sapienza, 2007, p. 434).

Wilner and Sataloff reported that the major problems encountered by singers pertain to poor vocal hygiene, including the use of improper breathing techniques, increased musculoskeletal tension, and poor resonance. The authors concluded that the voice team should collaborate to treat professional singers or speakers. Over the last few years, clinicians have come to agree that members of a voice care team should work collaboratively to provide treatment for professional voice users (Wilner, \& Sataloff, in Zeine, \& Waltar, 2002, p. 231). Sataloff et al. reported how cooperation between laryngologists, speech-language pathologists, and voice teachers has increased the clinician's ability to assess and treat voice pathologies in professional voice users (Sataloff, et al., in Zeine and Waltar, 2002, p. 231).

Despite the broad knowledge and high level of awareness of professional speakers about the culture of speech and care for voice organs, we conclude that there is much room for improvement and voice training of professional speakers - both in terms of grammar and pronunciation norms, as well as in other segments of spoken language, especially in maintaining the condition of voice and voice care.

\section{REFERENCES}

Broaddus-Lawrence, P., Treole, K., McCabe, R.B., Allen, R.B., \& Toppin, L. (2000). Habits and Perceptual Vocal Characteristics of Training Singers. Journal of Voice, 14(1). 58-71.

Lerner, M.Z., Paskhover, B., Acton, L., \& Young N. (2013). Voice Disorders in Actors. Journal of Voice, 27(6). 705-708.

Stankovič, J. (2011). Kultura govornega izražanja: na primeru Televizije Slovenija - Informativni program [Culture of spoken language: the case of Slovenian National Television]. Ljubljana: AGRFT.

Stankovič, J. (2013). Idealna govorna realizacija [Ideal speech realization]. In: H. Tivadar (Ed.). Aktualna vprašanja slovanske fonetike [Current issues of Slavic phonetics] (pp. 167-172). Ljubljana: Znanstvena 
založba Filozofske fakultete.

Stankovič, J., \& Tivadar, H. (2013). Preučevanje govorne in artikulacijske priprave govorca na javni govorni nastop [Speach and articulation lectures for public speaker appeareance]. In: K. Podbevšek, \& N. Žavbi Milojević (Eds.). Govor med znanostjo in umetnostjo [Speech between science and art] (pp. 131-138). Maribor: Aristej. Titze, I. R., Lemke, J., \& Montequin, D. (1997). Populationin the US workforce who rely on voice as a primary tool of trade: a prelimnibary report. Journal of Voice, 11(3). 254-259.

Varošanec-Škarić, G. (2010). Fonetska njega glasa i izgovora [Phonetic Voice care and Articulation]. Zagreb: FF press. Varošanec-Škarić, G., (2008): Acoustics characteristics of voice and vocal care in acting and other students. Clinical Linguistics \& Phonetics, 22(10-11). 881-889.

Velsvik Bele, I. (2007). Dimensionality in Voice Quality. Journal of Voice, 21(2). 257-272.

Vuletić, B. (1980). Gramatika govora [Speech grammatics]. Zagreb: Grafički zavod Hrvatske.

Wingate, J.M., Brown, W.S., Shrivastav R., Davenport, P., \& Sapienza, C.M. (2007). Treatment Outcomes for Professional Voice Users. Journal of Voice, 21(4). 433-449.

Zeine, L., \& Waltar, K. (2002): The Voice and Its Care: Survey Findings From Actors' Perspectives. Journal of Voice, 16(2). 229-243. 